\section{Tackling the obesity crisis: how do we 'measure up'?}

\author{
Alan A Jackson, Martin Wiseman, Stephen A Wootton
}

\section{BACKGROUND}

In early 2013, the Academy of Medical Royal Colleges (AoMRC) published the latest of several reports from various bodies over decades addressing aspects of the rising prevalence of obesity in the UK. ${ }^{1}$ Their report 'Measuring Up' made 10 recommendations targeted at the healthcare professions, at the obesogenic environment and towards making healthy choices the easy choices (box 1). The report made no claim to originality in describing the scale of the problem or in its selection of recommendations, derived from a wide ranging consultative process. It was, however, unusual in declaring the report to be the start of a campaign, and in its wide franchise in representing all the Medical Royal Colleges, and so indirectly virtually all medical practitioners in the UK. It is worth examining the contribution this particular report might make as part of its called-for campaign to solving what has up to now been a seemingly intractable problem.

The timing of the report and its contents must be seen in context. Obesity is acknowledged as among the most important aetiological factors for the development of chronic non-communicable diseases, which are now the major causes of ill-health and death on the planet. ${ }^{2-4}$ In 2011, the United Nations General Assembly for only the second time took health as the topic of its high-level meeting and used it to commit to addressing the prevention and treatment of chronic non-communicable diseases. ${ }^{5} 6$ In recognising this inextricably linked complex of challenges as a major global threat to the well-being of humankind, it adopted a resolution requiring international, regional, national and local cooperation to address the problem. During the 66th World Health Assembly in May 2013, member states of the $\mathrm{WHO}^{7}$ adopted an action plan for the prevention and control of non-

NIHR Southampton Biomedical Research Centre, Southampton General Hospital (MP113),

Southampton, UK

Correspondence to Professor Alan A Jackson, NIHR Southampton Biomedical Research Centre, Southampton General Hospital MP113, Tremona Road, Southampton S016 6YD, UK; aaj@soton.ac.uk communicable diseases, including the needs to adopt a life course approach, to have an equity-based approach which recognised the needs of mothers and children and to empower people and communities.

What is meant by a campaign in the AoMRC report remains unclear. A 'campaign' can be defined in various ways, but most simply can be seen as working in an organised and active way towards achieving a goal. Doctors can reasonably be charged with carrying a special responsibility within such a campaign, and in particular paediatricians, if they are to ensure that the voice of children is adequately represented. It is worth considering the role that doctors should play, how they could contribute to actively working in an organised way, identifying and overcoming the factors that limit effectiveness and in identifying and communicating the nature of the goal.

\section{IS THERE A PROBLEM?-YES. IS} THERE A NEED TO INTERVENE ?-YES

There is no doubt that excess adiposity carries serious risks of mortality and morbidity in adults, and increasingly in children, being a causal factor in the development of type 2 diabetes, cardiovascular disease, respiratory ill-health and several cancers. While the conventional definition of adult obesity as a body mass index (BMI) of $30 \mathrm{~kg} / \mathrm{m}^{2}$ or more cannot reliably distinguish lean from fat mass, it nevertheless serves to identify individuals at significant increased risk in the general population. $^{2}{ }^{3}$ In childhood, the changing relationship during growth in the rate of acquisition of height, lean mass and fat mass leads to a more complex relationship between weight and height and simple cut-off values that reliably mark risk of comorbidities have been more difficult to define. Thus, obesity in children is defined variously either as those with a BMI above the 95 th or 97 th centiles for age or lying above a growth trajectory that projects to BMI 30 at age $18 .^{8}$ The National Obesity Observatory and the National Child Measurement Programme use the definition of weight for age for populations above the 95th centile compared with the 1990 UK reference charts. However defined, high weight for height during childhood confers risk of immediate poor health and of later disease. It is clear that even during childhood, obesity is a cause of social and mental health problems. About a quarter of the adult population is now obese, compared with $7 \%$ in 1980 , and about a third of 9-year-olds are overweight or obese. It is estimated that the direct costs of obesity to the National Health Service are of the order of $£ 5$ billion annually, and the indirect costs to the economy as a whole substantially greater. By any measure, therefore, obesity is a serious social, medical and economic problem.

\section{ARE THE ENDS CLEAR?-YES. ARE THE MEANS CLEAR?-NO}

While everyone agrees that this is a problem, there is less consensus on what are effective measures for prevention or management. Why might this be? First, it is significant that the Academy's report is from the medical profession. Obesity has historically been framed as a medical issue and was not a major public health problem until after the Second World War. And while management of existing obesity clearly falls (at least partly) into the field of medicine or healthcare, the effective prevention of obesity is less clearly so. Public health approaches to prevention rely on identification of causes, and while physiological mechanisms represent a final common pathway for the excess energy consumption that leads to obesity, the environmental triggers that make susceptibility to it manifest are more complex. ${ }^{9}$

It would be difficult to make the case that the public, politicians, healthcare professions or the food, drink and leisure industries are unaware of the problem (even if the subtleties of body composition and eating behaviour are not always appreciated). Why then is there a need yet again to raise concern? The social, health and economic costs are great, but despite longstanding awareness and expressions of concern, there is little success in abating them. The medical profession is right to offer leadership on the issue in view of the health consequences, but equally leadership could come from economists or the public. The Academy report stakes a claim to be the start of a campaign, but the question arises as to what the campaign is for. Do the 10 recommendations set out represent an appropriate response to the nature of the problem?

\section{ARE THERE EXAMPLES OF SUCCESS? -NO AND YES}

To raise concern implies a reasonable appreciation of how to correct the 


\section{Action by the healthcare professions}

1. Education and training programmes for healthcare professionals: Royal Colleges, Faculties and other professional clinical bodies should promote targeted education and training programmes within the next 2 years for healthcare professionals in both primary and secondary care to ensure 'making every contact count' becomes a reality, particularly for those who have most influence on patient behaviour

2. Weight management services: The departments of health in the four nations should together invest at least $\mathrm{f} 100 \mathrm{~m}$ in each of the next three financial years to extend and increase provision of weight management services across the country, to mirror the provision of smoking cessation services. This should include both early intervention programmes and greater provision for severe and complicated obesity, including bariatric surgery. Adjustments could then be made to the Quality and Outcomes Framework, providing incentives for General Practitioners to refer patients to such services

3. Nutritional standards for food in hospitals: Food-based standards in line with those put in place for schools in England in 2006 should be introduced in all UK hospitals in the next 18 months. Commissioners should work with a delivery agent similar to the Children's Food Trust to put these measures into place

4. Increasing support for new parents: The current expansion of the health visitor workforce in England should be accompanied by skilling up the wider early years workforce to deliver basic food preparation skills to new mothers and fathers, and to guide appropriate food choices which will ensure nutritionally balanced meals, encourage breast feeding and use existing guidance in the Personal Child Health Record as a tool to support this.

The obesogenic environment

5. Nutritional standards in schools: The existing mandatory food-based and nutrient-based standards in England should be applied to all schools, including free schools and academies. This should be accompanied by a new statutory requirement on all schools to provide food skills, including cooking, and growing - alongside a sound theoretical understanding of the long-term effects of food on health and the environment from the 2014/2015 academic year

6. Fast food outlets near schools: Public Health England should, in its first 18 months of operation, undertake an audit of local authority licensing and catering arrangements with the intention of developing formal recommendations on reducing the proximity of fast food outlets to schools, colleges, leisure centres and other places where children gather

7. Junk food advertising: A ban on advertising of foods high in saturated fats, sugar and salt before 21:00, and an agreement from commercial broadcasters that they will not allow these foods to be advertised on internet 'on-demand' services

Making the healthy choice the easy choice

8. Sugary drinks tax: For an initial 1 year, a duty should be piloted on all sugary soft drinks, increasing the price by at least $20 \%$. This would be an experimental measure, looking at price elasticity, substitution effects and to what extent it impacts upon consumption patterns and producer/retailer responses

9. Food labelling: Major food manufacturers and supermarkets should agree in the next year a unified system of traffic light food labelling (to be based on percentage of calories for men, women, children and adolescents) and visible calorie indicators for restaurants, especially fast food outlets

10. The built environment: Public Health England should provide guidance to Directors of Public Health in working with Local Authorities to encourage active travel and protect or increase green spaces to make the healthy option the easy option. In all four nations, local authority planning decisions should be subject to a mandatory health impact assessment, which would evaluate their potential impact upon the populations' health.

situation. The implication is clear that if the 10 recommendations were to be followed, then there is a reasonable expectation that the pervasive and insidious increase in the problem would be halted.
But do we know what works (efficacy), and can it be sustained and developed at scale (effectiveness)?

There are many examples of interventions that can reduce excess weight based on diet, behaviour change and physical activity. Using schools as a setting appears to be a particularly valuable opportunity to support change. ${ }^{9-14}$ Successful interventions are characterised by highly motivated individuals or groups. Translating efficacy into effectiveness is a different challenge. The Health Technology Assessment Programme has reviewed success at scale in adults within a medical model of interventions. Modest success in the short term can be achieved with approaches that require either behaviour change ${ }^{15}$ or drug therapy, ${ }^{16}$ but this is not sustained, especially in the absence of ongoing support. Indeed, the only reliably effective treatment is bariatric surgery, and sustained weight loss is directly associated with reversal of comorbidities. ${ }^{17}{ }^{18}$ It also appears to be effective in prevention, as, for example, with a decreased incidence of breast cancer. ${ }^{19}$ However for a variety of reasons, including but not only the risk of adverse effects from the intervention, it is hard to see this approach as a suitable solution for a problem affecting a majority of the population to a greater or lesser degree; this demands a public health approach that goes beyond a medical model.

The introduction of a structured framework within which to conduct environmental modifications, the Analysis Grid for Elements Linked to Obesogenic Environments (ANGELO), has facilitated comparative evaluations. ${ }^{20} 21$ The most extensive study using this approach to explore structured changes to the obesogenic environment and as the basis for a range of interventions was carried out in different communities in Australia, New Zealand and South Pacific Islands. ${ }^{22}$ The impact was depressingly small, and there was a measure of despair in the conclusion that it was imperative to reach beyond the medical community to wider society to achieve any success. ${ }^{23}$ Is there evidence for this? In Cuba, the loss of the USSR as a trading partner in 1989 led to a serious constraint of resources with economic output reaching a nadir in 1995 and recovery not being realised until 2000 , and a severe reduction in food availability necessitating food rationing. There was a concomitant increase in energy expenditure, as fuel shortages limited availability of motorised transportation, and the population had to revert to manual labour. ${ }^{24} 25$ There was a population-wide fall in BMI of 1.5 units, accompanied by reduced morbidity and mortality, which reversed as resources became available once again, with some evidence of BMI overshoot. ${ }^{24}$ Finland is 
held as a model in terms of policy change that has substantially decreased the risk of chronic non-communicable disease. Across the age range, most of the population have BMI values associated with the lowest morbidity and mortality, but even here there is evidence of increasing prevalence of overweight and obesity. ${ }^{26} 27$

The one example of seeming sustained success is the experience of the EPODE (Ensemble, Prevenons l'Obesite des Enfants) study, based on the experience in villages in Northern France, ${ }^{28}$ where top-down policy was matched by bottom-up, community-based engagement, with sustained improvements in childhood weight. Although limited and not at scale, the approach has been followed in many other communities around the world. This positive experience offers opportunity as it appears that when a community decides to ensure that those factors that contribute to an unhealthy environment are simply not acceptable, and so not accepted, improved health can follow. ${ }^{29}$ However, it is not clear that the AoMRC approach incorporates a strong bottom-up element.

\section{CAN DOCTORS USEFULLY LEAD A CAMPAIGN?}

Obesity is a complex problem-the result of the interaction of a range of complicated biological and social factors, with a final common pathway of personal psychological and physiological factors. For many countries, and for many families, the benefits brought by development or 'progress' conspire to increase the risk of becoming obese. Sustained change will require that any shift in attitudes enables people and groups to 'swim with the tide, not against the current'. A healthy environment-conducive to healthy eating and an active lifestyle-needs to become the default, rather than the niche choice of more affluent groups. Food and culture and the behaviours around food acquisition, eating and cuisine embrace the essence of a society's values.

What might be the roles for doctors? How can they best use the respect and regard in which they are held to address both the prevention and the management of obesity while avoiding the blame game? The Nuffield Foundation has offered a ladder of intervention for public health, with obesity as one example. ${ }^{30}$ This highly regarded ladder is now widely used, but is structured around single actions. This is not sufficient for a complex situation, where the interaction of biomedical, social and economic considerations rubs against the social drivers for progress, and our very perception of the nature of progress. For some, the food industry has been demonised because of the appearance that economic drivers outweigh health considerations. A recent report in which the food industry has started to explore its own performance and responsibilities, assessing how well they meet defined standards of conduct suggests a more critical self-reflection. ${ }^{31}$ It might be too much to hope that society is ready for a dialogue that cuts across all sectors and sectoral interests, but perhaps this is exactly what could be achieved by a campaign or movement led by the medical profession. This might include a clear articulation of the damage that can be wrought by that essential component of living, food; discussion, and strong and consistent argument about the ways forward while placing human well-being at the heart of society's aspirations and being clear about the enormous economic cost of doing nothing compared with the enormous benefit of clear, decisive and coordinated action across all sectors.

One important question is why doctors have been slow to engage with the problem of obesity and take responsibility more fully. One consideration is that it is a diet and nutritionally related conditionan area where clinicians are notoriously poorly trained. The increasingly obvious comorbidities place the problem in a context that is more comfortable for clinicians, but paradoxically draws attention away from the underlying socioeconomic causes. The costs and difficulties in managing the consequences of obesity-both medical and social-mean that it can no longer be ignored. The call for a campaign is welcome, but better training in nutrition of all doctors and other health workers will be essential to provide the necessary knowledge and skills. The AoMRC report might have addressed their own constituency-doctors-more explicitly in this regard. The Academy Nutrition Group in the AoMRC has developed an undergraduate curriculum in nutrition for trainee doctors, which has been commended by the General Medical Council and is signposted in Tomorrow' Doctors. ${ }^{32}$ But until this undergraduate training is more widely embedded, the Intercollegiate Course in Human Nutrition overseen by the AoMRC is currently the only structured course for doctors in the basic principles of nutrition ${ }^{33}$ (http://www.aomrc. org.uk/committees/intercollegiate-group-onnutrition.html).

The AoMRC report presents a challenge to doctors. We need to build the capability and capacity to address the challenge-this means not just training those working in obvious health fields, but ensuring that those in other sectors of society that impact on the obesogenic environment also see it as their problem. Further, there is the need for willingness and commitment to act to make sustained and coherent change across all sectors, within a single framework to address this major risk to future health. Individual paediatricians-and other doctorsshould reflect on how they can contribute in their own practice to achieving this public health goal.

Acknowledgements We acknowledge support to the NIHR Southampton Biomedical Research.

Competing interests None.

Provenance and peer review Commissioned; externally peer reviewed.

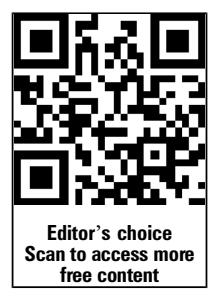

To cite Jackson AA, Wiseman M, Wootton SA. Arch Dis Child 2014;99:95-98.

Received 30 August 2013

Accepted 23 October 2013

Published Online First 15 November 2013

Arch Dis Child 2014;99:95-98.

doi:10.1136/archdischild-2013-304034

\section{REFERENCES}

1 Academy of Medical Royal Colleges. Measuring Up the medical profession's prescription for the Nation's obesity crisis. London: Academy of Medical Royal Colleges, 2013. http://www.aomrc.org.uk/ publications/statements/doc_view/9673-measuringup.html

2 Swinburn BA, Sacks G, Hall KD, et al. The global obesity pandemic: shaped by global drivers and local environments. Lancet 2011;378:804-14.

3 Flegal KM, Kit BK, Orpana $\mathrm{H}$, et al. Association of all-cause mortality with overweight and obesity using standard body mass index categories: a systematic review and meta-analysis. JAMA 2013;309:71-82.

4 World Health Organization. 2008-2013 Action Plan for the Global Strategy for the Prevention and Control of Noncommunicable Diseases. 2008. http:// whqlibdoc.who.int/publications/2009/ 9789241597418_eng.pdf

5 Secretary General. Prevention and control of non-communicable diseases. Report of the Secretary-General 66th session of General Assembly. 2011. http://www.un.org/ga/search/view_doc.asp? symbol=A/66/83\&Lang $=E$

6 United Nations General Assembly. Political declaration of the High-level Meeting of the General Assembly on the Prevention and Control of Non-communicable Diseases. 2011. http://www.un org/ga/search/view_doc.asp?symbol=A/66/L.1

7 World Health Organization. Global action plan for the control of non-communicable Diseases. Geneva: 
World Health Organization, 2013. http://apps.who. int/gb/ebwha/pdf_files/WHA66/A66_9-en.pdf

8 Scientific Advisory Committee on Nutrition and Royal College of Paediatrics and Child Health. Consideration of issues around the use of BMI centile thresholds for defining underweight, overweight and obesity in children aged 2-18 years in the UK. 2012. http://www.sacn.gov.uk/pdfs/ sacnrcpch_position_statement_bmi_thresholds.pdf

9 Rutter $\mathrm{H}$. Where next for obesity? Lancet 2011;378:747-8.

10 Flynn MAT, McNeil DA, Maloff B, et al. Reducing obesity and related chronic disease risk in children and youth: a synthesis of evidence with "best practice" recommendations. Obes Rev 2006; 7(Suppl 1):7-66.

11 Gonzalez-Suarez C, Worley A, Grimmer-Somers K, et al. School-based interventions on childhood obesity: a meta-analysis. Am J Prev Med 2009;37:418-27.

12 Brown T, Summerbell C. Systematic review of school-based interventions that focus on changing dietary intake and physical activity levels to prevent childhood obesity: an update to the obesity guidance produced by the National Institute for Health and Clinical Excellence. Obes Rev 2009;10:110-41.

13 Waters E, de Silva-Sanigorski A, Hall BJ, et al. Interventions for preventing obesity in children. Cochrane Database Syst Rev 2011;(12):CD001871.

14 Nixon CA, Moore HJ, Douthwaite W, et al. ToyBox-study group. Identifying effective behavioural models and behaviour change strategies underpinning preschool- and school-based obesity prevention interventions aimed at 4-6-year-olds: a systematic review. Obes Rev 2012;13(Suppl 1): 106-17.

15 Loveman E, Frampton GK, Shepherd J, et al. The clinical effectiveness and cost-effectiveness of long-term weight management schemes for adults: a systematic review. Health Technology assessment
2011, 15 No 2. http://www.journalslibrary.nihr.ac. uk/_data/assets/pdf_file/0005/61277/ ExecutiveSummary-hta15020.pdf

16 Ara R, Blake L, Gray L, et al. What is the clinical effectiveness and cost-effectiveness of using drugs in treating obese patients in primary care? A systematic review. Health Technology Assessment 2012, 16 No 5. http://www.journalslibrary.nihr.ac.uk/_data/assets/ pdf_file/0020/59240/ExecutiveSummary-hta16050. pdf

17 Picot J, Jones J, Colquitt JL, et al. The clinical effectiveness and cost-effectiveness of bariatric (weight loss) surgery for obesity: a systematic review and economic evaluation. Health Technology Assessment 2009, 13 No 41. http://www. journalslibrary.nihr.ac.uk/_data/assets/pdf_file/0017/ 61154/ExecutiveSummary-hta13410.pdf

18 Sjostrom L. Review of the key results from the Swedish Obese Subjects (SOS) trial—a prospective controlled intervention study of bariatric surgery. J Intern Med 2013;273:219-34.

19 Byers T, Sedjo RL. Does intentional weight loss reduce cancer risk? Diab Obes Metab 2011;13:1063-72.

20 Swinburn B, Egger G, Raza F. Dissecting obesogenic environments: the development and application of a framework for identifying and prioritizing environmental interventions for obesity. Prev Med 1999;29:563-70

21 Kirk SF, Penney TL, McHugh T-LF. Characterizing the obesogenic environment: the state of the evidence with directions for future research. Obes Rev 2010;11:109-17.

22 Simmons A, Mavoa HM, Bell AC, et al. Creating community action plans for obesity prevention using the ANGELO (Analysis Grid for Elements Linked to Obesity) framework. Health Promot Int 2009;24:311-24

23 Uauy R, Corvalan C, Kain J. Forward: pacific Obesity Prevention in Communities (OPIC) project. Obes Rev 2011;12(Suppl 2):1-2.
24 Franco M, Ordunez P, Caballero B, et al. Impact of energy intake, physical activity, and population-wide weight loss on cardiovascular disease and diabetes mortality in Cuba, 1980-2005. Amer J Epidemiol 2007;166:1374-80.

25 Franco M, Bilal U, Ordunez P, et al. 2013. Population-wide weight loss and regain in relation to diabetes burden and cardiovascular mortality in Cuba 1980-2101: repeated cross sectional surveys and ecological comparison of secular trends. BMJ 2013;346:f1515

26 Vuorela N, Saha M-T, Salo MK. Change in prevalence of overweight and obesity in Finnish children-comparison between 1974 and 2001. Acta Paediatrica 2011;100:109-15.

27 Prattala R, Sippola R, Lahti-Koski M, et al. Twenty-five year trends in body mass index by education and income in Finland. BMC Public Health 2012:12:936-43.

28 Borys Jm, Le Bodo Y, Jebb SA, et al., EEN Study Group. EPODE approach for childhood obesity prevention: methods, progress and international development. Obes Rev 2012;13: 299-315.

29 Van Koperen TM, Jebb SA, Summerbell CD, et al. Characterizing EPODE logic model: unravelling the past and informing the future. Obes Rev 2013:14:162-70.

30 Nuffield Council on Bioethics. Public health: ethical issues. Cambridge, UK: Cambridge Publishers Ltd, 2007

31 Access to Nutrition Index. Global Index 2013. http:/ s3.amazonaws.com/ATN/atni_global_index_2013.pdf

32 General Medical Council 2009. Tomorrow's Doctors: outcomes and standards for undergraduate medical education. http://www.gmc-uk.org/Tomorrows Doctors_2009.pdf_39260971.pdf

33 Jackson AA. Human nutrition in medical practice: the training of doctors. Proc Nutr Soc 2001;60: 257-63. 